\title{
Three new genera with taxonomic revisions of the subfamily Coelotinae (Araneae: Agelenidae) from Japan
}

\author{
Ken-ichi Okumura \\ Department of Zoology, National Museum of Nature and Science, 4-1-1 Amakubo, Tsukuba, Ibaraki 305-0005, Japan \\ E-mail: okumura@kahaku.go.jp
}

\begin{abstract}
There are currently doubts about the correct genus of many Japanese species of coelotine spider provisionally classified in the genus Coelotes. Thus, taxonomic revisions were performed on 16 species with two retromarginal teeth on their chelicerae. Consequently, three new genera of the subfamily Coelotinae are described here. Aeolocoelotes gen. n. consists of seven species, which are characterized by extremely diverse variations in their genital organs and by the clear parapatric distributions among the congeneric species. Individuals in Aeolocoelotes gen. $n$. have large and dark-colored bodies, and females have a stiff chitinous epigyne. Curticoelotes gen. n. consists of six species, which are characterized by a short cymbium in the male palp. Finally, Griseidraconarius gen. n. consists of three species, which are characterized by their pale-colored bodies, spiraled conductors in the male palp, and tiny epigynal teeth.
\end{abstract}

Key words - biogeography, DNA barcoding, morphology, taxonomy, two retromarginal teeth

\section{Introduction}

Coelotine spiders are found throughout the Holarctic and Oriental regions, with 773 species having been described to date (World Spider Catalog 2020). Many of the species included in this group are similar to each other in appearance; hence, the comparative morphology of the genital organs of both sexes is especially important in the taxonomy of the subfamily Coelotinae F. O. Pickard-Cambridge 1893. In the classification of coelotine spiders, not only genital organs but also the number of the retromarginal teeth on the chelicerae are regarded as important morphological characteristics; accordingly, some detailed studies of these spiders, including one based on the presumption of a phylogenetic relationship, have been conducted (Wang 2002, 2003; Wang \& Jäger 2008, 2010). In recent years, molecular phylogenetic analyses have been actively performed to clarify the taxonomy and phylogeny of coelotine spiders (Bi et al. 2005; Chen et al. 2015a, b, 2016; Li et al. 2018a, b, c, 2019a, b; Miller et al. 2010; Okumura et al. 2016, 2017, 2019; Spagna \& Gillespie 2008; Zhang \& Marusik 2016; Zhang et al. 2016a, b; Zhao \& Li $2016,2017)$. These new methods have enabled more objective analyses based on DNA base sequences, and their importance is increasing relative to other forms of morphological analysis. Nevertheless, morphological analyses that have been developed through trial and error by many researchers remain vitally important. Indeed, the molecular and morphological data used in the taxonomy of coelotine spiders should ideally be complementary each other.
In Japan, 121 species of coelotine spiders have been discovered to date (World Spider Catalog 2020), and many of these species have been discovered since the year 2000 (Nishikawa 2009; Okumura 2007, 2010, 2013, 2017, 2019; Okumura \& Ono 2006; Okumura et al. 2011; Ono 2008; Shimojana 2000a, b; Shimojana \& Nishihira 2000). During the process of researching the distributional range and species composition of coelotine spiders, it has become clear that some morphological characteristics, hitherto used for classification purposes, are unstable and rich in geographical variation. Therefore, there remain doubts about the correct genus of many species provisionally classified into the genus Coelotes Blackwall 1841. From recent studies, it has become especially apparent that most species with two retromarginal teeth on the chelicerae are phylogenetically different from the genus Coelotes; consequently, seven new genera have been established from China since 2015 (Chen et al. 2015b; Li et al. 2018a, c, 2019a, b; Zhao \& Li 2016). Importantly, the number of retromarginal teeth on the chelicerae is extremely stable only in species that have two teeth; variations in the number of retromarginal teeth occur at a constant rate in species that have three or four retromarginal teeth, but the number of teeth rarely decreases to two in these species ( $0 \%$ for species with four teeth) (Okumura 2009). This also serves as the evidence that the species group with two retromarginal teeth on the chelicerae is phylogenetically different from the genus Coelotes.

In this present study of the genus Coelotes from Japan, I reconsider the taxonomic status of the species group with 
Table 1. Samples with collection localities and INSDC accession numbers.

\begin{tabular}{llll}
\hline Species & sex & Collection localities & Accession No. \\
\hline Aeolocoelotes bifurcatus & male & Mt. Yasuman-dake, 500m alt., Hirado City, Nagasaki Pref. & LC549488 \\
Aeolocoelotes personatus & female & Mt. Ibuki, 1230m alt., Maibara City, Shiga Pref. & LC549492 \\
Aeolocoelotes saikaiensis & female & Mt. Yuri-dake, 160m alt., Oshima Town, Saikai City, Nagasaki Pref. & LC549493 \\
Aeolocoelotes unicatus & male & Haramaki, Sefuri Town, Kanzaki County, Saga Pref. & LC549494 \\
Aeolocoelotes unzenensis & female & Mt. Hidake, 230m alt., Imamura Town, Omura City, Nagasaki Pref. & LC549495 \\
Curticoelotes hiradoensis & male & Mt. Yasuman-dake, 500m alt., Hirado City, Nagasaki Pref. & LC549490 \\
Curticoelotes kintaroi & male & Mt. Hakkouda, 760m alt., Aomori City, Aomori Pref. & LC549491 \\
Curticoelotes hamamurai & female & Appi-kogen, 820m alt., Hachimantai City, Iwate Pref. & LC549496 \\
Griseidraconarius decolor & female & Nishiumi Town, Nagasaki City, Nagasaki Pref. & LC549489 \\
\hline
\end{tabular}

two retromarginal teeth by using morphological characteristics that have previously been regarded as important for the classification of coelotine spiders. Where it was necessary, genetic data were also used to complement these morphological observations. From my results, it became clear that many species from Japan should be classified into several groups. I therefore describe and argue for three new genera of coelotine spiders on the basis of 16 species. Among the Japanese species that have not been the subject of molecular analysis to date, there are many other species with two retromarginal teeth on the chelicerae. Thus, it will also be necessary to continue with similar studies on these species.

\section{Materials and Methods}

\section{Sampling and morphological examination}

All the materials were collected from Japan. Examinations were performed using an Olympus SZX-7 stereomicroscope. In order to examine the genital organs, the left male palp was removed as necessary. To examine the female internal genitalia, the epigyne was dissected and treated with a $10 \% \mathrm{KOH}$ solution to remove the muscle. Photographs were taken using an Olympus E-620 digital camera attached to the microscope. Respective body parts were measured using a micrometer mounted on an ocular lens. All measurements are given in $\mathrm{mm}$. The abbreviations used in this study are as follows: ALE, anterior lateral eye; AME, anterior median eye; CDA, conductor dorsal apophysis; LTA, lateral tibial apophysis; and RTA, retrolateral tibial apophysis. For the species classified into the new genera in this study, additional explanations were necessary besides the original description, so the genital organs of seven species were re-described.

\section{Molecular analysis}

Nine specimens from the obtained samples were used for molecular analysis. The details of these samples are shown in Table 1. To conduct molecular analysis, previously published data for six species (LC382466, LC440635, LC440636, LC440637, LC440639, and KY778854) were first obtained from the International Nucleotide Sequence Database Collaboration (INSDC). Mitochondrial cytochrome oxidase subunit I (mt-COI) was amplified using the primer combination COI-1628 and COI-Nancy (Vandergast et al. 2004). DNA extraction, polymerase chain reaction, and sequencing methods were adopted from the methods of Okumura et al. (2016). The LALIGN Server was used to analyze the genetic distances among each species. The DNA sequences newly obtained in this study have been deposited with INSDC through the DNA Data Bank of Japan (Table 1).

\section{Results and Discussion}

As a result of amplification and sequencing, mt-COI partial sequences of $522 \mathrm{bp}$ in length were obtained. The genetic data were mainly used to confirm affinities among congeneric species. Results of molecular analysis and their reliability, as judged by comparison with other data, are reported below. The specimens examined in this study can be divided into three groups based on their morphological characteristics as follows. The first species group contains coelotine spiders with a large, dark-colored body and strongly chitinized genital organs. The second species group contains individuals with a short cymbium in the male palp. The third species group includes those with a pale-colored body and tiny epigynal teeth in the female genitalia. Based on these groups, three new genera of coelotine spiders are described here: Aeolocoelotes gen. n., Curticoelotes gen. n., and Griseidraconarius gen. n., respectively. Furthermore, the relationships within each genus are confirmed. According to detailed observation of morphological characteristics and the results of molecular analysis, Aeolocoelotes and Curticoelotes are further divided into two species groups.

Aeolocoelotes consists of seven species; A. unicatus (Yaginuma 1977) comb. n. was designated as the type species. The p-distances (i.e., the number of base differences per total number of analyzed bases) of $A$. sanoi (Nishikawa 2009) comb. n. and A. mohrii (Nishikawa 2009) comb. n. from the type species $A$. unicatus were 0.077 and 0.067 , respectively (p-distances from A. unicatus were 0.108-0.117 in the four 
other species). In previous studies, clear parapatric distributions among the species of Aeolocoelotes have been shown (Okumura et al. 2019; Okumura unpublished data). This distribution pattern also provides evidence that these species are closely related.

Curticoelotes consists of six species; C. hiradoensis (Okumura \& Ono 2006) comb. n. was designated as the type species. The p-distances of C. oxyacanthus (Okumura 2013) comb. n., C. kintaroi (Nishikawa 1983) comb. n., and $C$. hamamurai (Yaginuma 1967) comb. n. from the type species C. hiradoensis were $0.125,0.161$, and 0.172 , respectively. It is clear that these four species are closely related based on the characteristics of the genital organs of both sexes. Molecular analysis was not conducted on the other two species, C. sawadai (Nishikawa 2009) comb. n. and C. taurus (Nishikawa 2009) comb. n.; however, taxonomic revisions of these two species, which clearly share morphological characteristics with $C$. hiradoensis and $C$. oxyacanthus, were performed. The above four species uniquely possess a short cymbium in the male palp in addition to the overall similarity of the genital organs of both sexes and the consistently small body size.

Griseidraconarius consists of three species; G. decolor (Nishikawa 1973) comb. n. was designated as the type species. The p-distances of G. akakinaensis (Shimojana 2000) comb. n. and G. iriei (Okumura 2013) comb. n. from the type species $G$. decolor were 0.103 and 0.090 , respectively. $G$. decolor was closer by genetic distance to Draconarius venustus Ovtchinnikov 1999, the type species of the genus Draconarius (p-distance $=0.109)$, than were the type species of the other two new genera (A. unicatus: p-distance $=0.135 ; C$. hiradoensis: $\mathrm{p}$-distance $=0.144)$. In terms of morphological characteristics, the three species of Griseidraconarius have similarly pale-colored bodies, spiraled conductors of the male palp, and tiny epigynal teeth.

There is the possibility that Aeolocoelotes and Curticoelotes could be further subdivided because both of these new genera consist of two species groups. However, further analysis will be required to confirm these potential subdivisions.

\section{Taxonomy}

Family Agelenidae C. L. Koch 1837

Subfamily Coelotinae F. O. Pickard-Cambridge 1893

Aeolocoelotes gen. n.

(Japanese name: Saigoku-yachigumo-zoku)

Type species. Coelotes unicatus Yaginuma 1977 (preserved in the collection of the Osaka Museum of Natural History).

Etymology. The generic name is a compound noun derived from the Greek aiolos "great diversity" and the existing generic name Coelotes, and it refers to the high number of morphological variations of the genital organs among and within species. The gender is masculine.

Diagnosis. By comparison with other genera that have two retromarginal teeth on their chelicerae, the new genus is characterized by a large, dark-colored body. The males of the genus can be distinguished from individuals in other genera by a palp with a large and robust conductor and a thick embolus (Figs. 1A-C; 2A-D). The female can be distinguished by a chitinous epigyne swelling on both lateral sides or on the anterior portion (Figs. 1D-F; 2E-H).

Composition. Two species groups consisting of seven species as follows:

\section{Species group of Aeolocoelotes unicatus}

Aeolocoelotes unicatus (Yaginuma 1977) comb. n. Aeolocoelotes mohrii (Nishikawa 2009) comb. n. Aeolocoelotes sanoi (Nishikawa 2009) comb. n.

\section{Species group of Aeolocoelotes unzenensis}

Aeolocoelotes personatus (Nishikawa 1973) comb. n. Aeolocoelotes bifurcates (Okumura \& Ono 2006) comb. n. Aeolocoelotes unzenensis (Okumura 2013) comb. n. Aeolocoelotes saikaiensis (Okumura 2013) comb. n.

Description. Medium- to large-sized coelotine spiders, 9.0-16.0 $\mathrm{mm}$ in length. Cheliceral promargin with three teeth, retromargin with two. Leg formula IV-I-II-III. Carapace blackish brown with indistinct radial flecks or no spots; dorsum of abdomen blackish brown with gray chevrons or irregular flecks, and venter yellowish brown without flecks; sternum blackish brown; chelicerae, maxillae, and labium almost black; legs blackish brown without ring flecks.

Male. Palp (Figs. 1A-C; 2A-D): various forms present for each species. Patellar apophysis present in four species (A. unicatus, A. sanoi, A. mohrii, and A. bifurcatus), absent in two species (A. unzenensis and A. saikaiensis), and almost reduced in $A$. personatus; LTA small or absent; RTA large; conductor thick and robust, especially sword-shaped in $A$. unzenensis, $A$. bifurcatus, and $A$. saikaiensis; median apophysis bifurcate in $A$. unzenensis and $A$. bifurcatus, reduced in $A$. personatus, and spoon-shaped in other species; embolus thick and short.

Female. Epigyne (Figs. 1D-F; 2E-H): anterior portion or both lateral sides of epigynal plate protuberant; epigynal teeth nipple-shaped in A. bifurcatus, absent in A. unzenensis, conglutinated together in A. mohrii, A. saikaiensis, and $A$. personatus; clear and deep atrium present in $A$. unicatus, $A$. sanoi, and $A$. mohrii.

Distribution. Japan (Honshu, Shikoku, Kyushu).

Remarks. Aeolocoelotes gen. n. is divided into two species groups as a result of molecular analysis. However, it is appropriate to treat these two groups as a congeneric considering the similarity of the male palp among $A$. unicatus, A. sanoi, and $A$. saikaiensis, and of the epigyne between $A$. mohrii and $A$. bifurcatus. In addition, six species except $A$. personatus clearly show parapatric distributions (Fig. 3). These distribution patterns are also evidence that the two groups are congeneric.

Aeolocoelotes unicatus (Yaginuma 1977) comb. n. (Figs. 1A, 1D) 


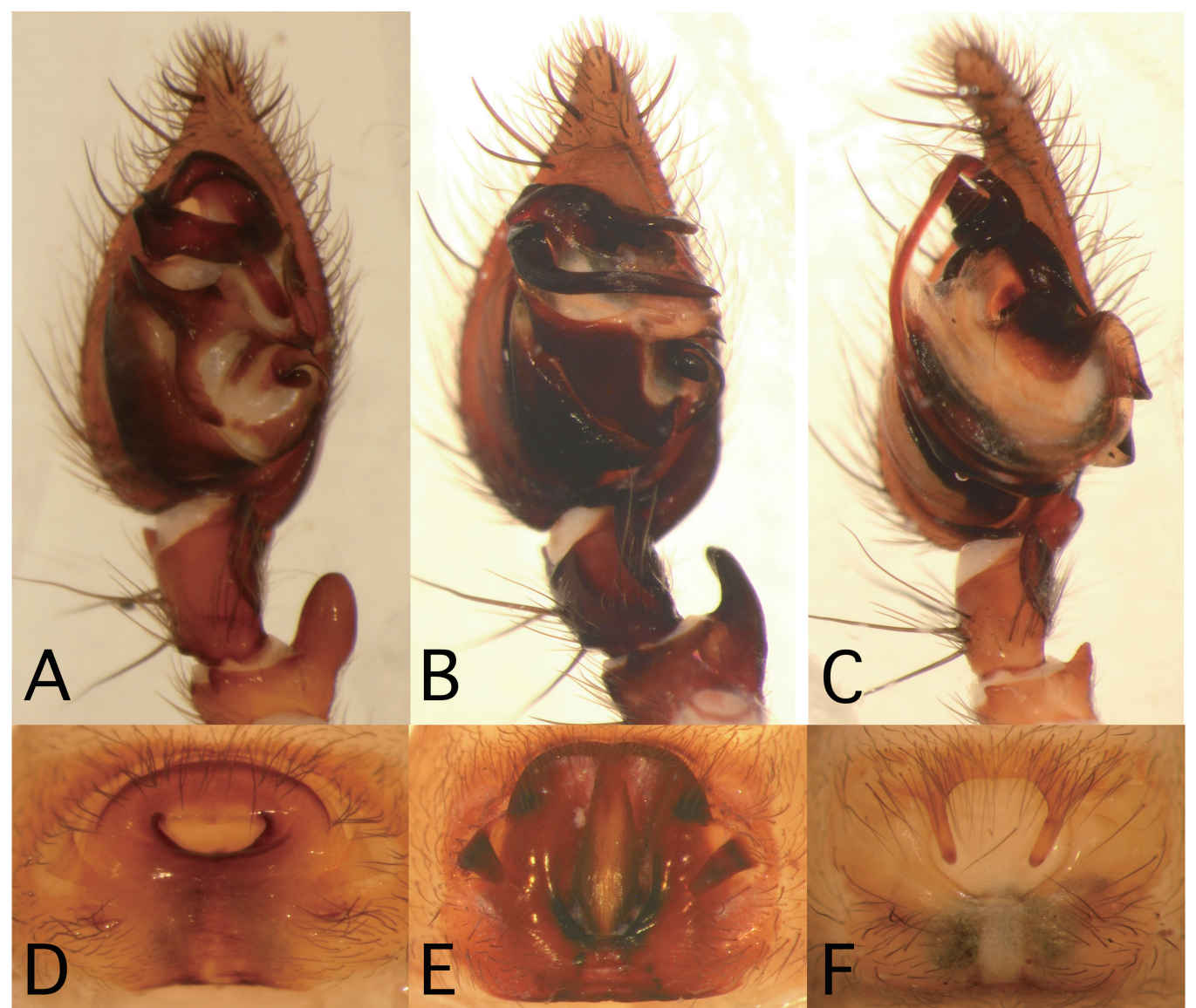

Fig. 1. Comparison of genitalic characters of three species of Aeolocoelotes gen. n. (species group of A. unicatus) from Japan: A, D, A. unicatus (Yaginuma 1977), B, E, A. sanoi (Nishikawa, 2009), C, F, A. mohrii (Nishikawa 2009). A, B, C, ventral views of male palp; D, E, F, ventral views of epigyne.

Coelotes unicatus Yaginuma 1977, pp.14-16, figs. 13-14; Yaginuma 1986, p. 151, fig. 82-10; Irie 1985, p. 7, fig. 4; Okumura et al. 2009 , p. 187, figs. 2-2-33-167-2-2-33-170; Okumura, Noine \& Ohba 2016, p. 74, fig. 1A-D.

Diagnosis. Genital organs of A. unicatus are most similar to those of $A$. sanoi. For the differences between the two species, refer to Okumura et al. (2016).

Description. Male: total length 10.0-13.0 mm. Palp (Fig. 1A): patellar apophysis thick with small accessory tooth on dorsum; LTA minute, agglutinated with dorsum of RTA; cymbial furrow about one-half of cymbial length; conductor stout and extended to the base of the cymbium obliquely; trifurcate brown plate situated in the central portion of the tegulum; median apophysis spoon-shaped; embolus thick.

Female: total length 9.0-15.0 mm. Epigyne (Fig. 1D): epigyne generally oval-shaped or trapezoid, but rich in morphological variations; atrium presented as a remarkable hollow situated in the anterior or central portion of the epigyne, and swollen in its outer edge; epigynal teeth short and trian- gular, situated distantly from each other in the lateral sides of the epigyne.

Morphological variations. Intraspecific variations are shown markedly in the shape of the epigyne, and are especially present in its atrium (Fig. 4). Variations are diverse, continuous, and occur only in female specimens. For the shape of the male palp in each locality, refer to Fig. 5.

Distribution. Western Japan (Honshu, Shikoku, Kyushu) (Figs. 3-5).

Aeolocoelotes mohrii (Nishikawa 2009) comb. n. (Figs. 1C, 1F)

Coelotes mohrii Nishikawa 2009, p.64, figs. 2-1-80-2-1-81; Okumura et al. 2009, p. 184, fig. 2-2-33-159; Okumura, Honki \& Ohba 2019, p. 5 , fig. 4 .

Coelotes iyoensis Nishikawa 2009, p. 70, figs. 2-1-108-2-1-110; Okumura et al. 2009, p. 184, figs. 2-2-33-358-2-2-33-359.

Diagnosis. The shape of the male palp in $A$. mohrii is 


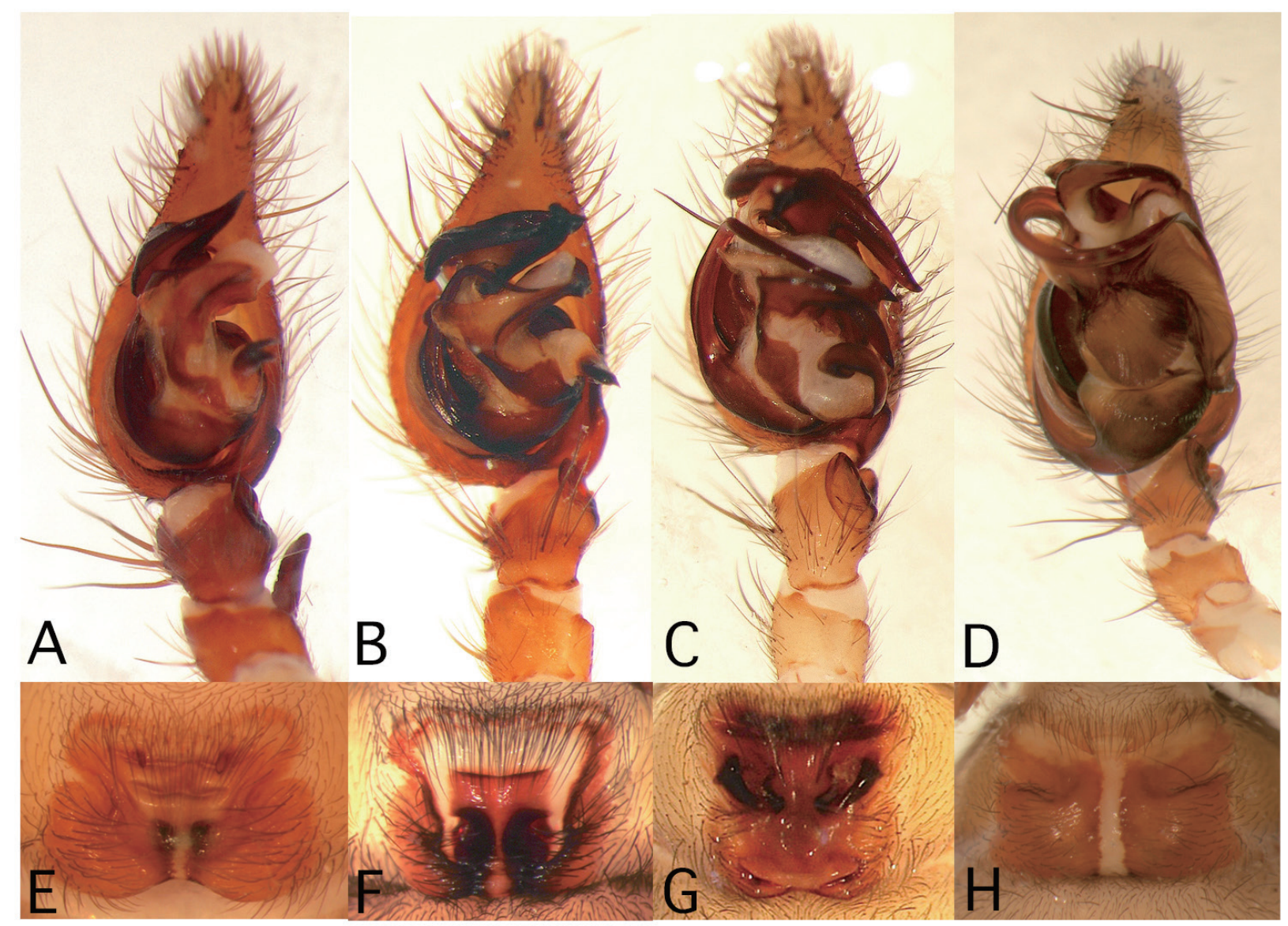

Fig. 2. Comparison of genitalic characters of four species of Aeolocoelotes gen. n. (species group of A. unzenensis) from Japan: A, E, A. bifurcatus (Okumura \& Ono 2006), B, F, A. unzenensis (Okumura 2013), C, G, A. saikaiensis (Okumura 2013), D, H, A. personatus (Nishikawa 1973). A, B, C, D, ventral views of male palp; E, F, G, H, ventral views of epigyne.

unique, and is clearly distinguished from that of other coelotine spiders. For details, refer to Okumura et al. (2019). The epigyne of this species is similar to that of $A$. bifurcatus, but is distinguishable by the longer epigynal teeth relative to those of the latter species.

Description. Male: total length 10.0-12.0 mm. Palp (Fig. 1C): patellar apophysis small; LTA small and indistinct; RTA large; cymbial furrow about two-fifths of cymbial length; conductor short and situated toward the base of the cymbium obliquely; median apophysis spoon-shaped, and located on the retrolateral side of the tegulum; embolus extends in a counterclockwise direction (left palp) from the anterior end of the genital bulb.

Female: total length 10.0-13.0 mm. Epigyne (Fig. 1F): epigyne reverse trapezoid-shaped; atrium situated in the anterior portion of the epigyne, and swollen in its outer edge; epigynal teeth conglutinated together in the anterior portion and not pointed.

Distribution. Ehime Prefecture, Japan (Fig. 3).
Aeolocoelotes sanoi (Nishikawa 2009) comb. n.

(Figs. 1B, 1E)

Coelotes sanoi Nishikawa 2009, p.64, fig. 2-1-82; Okumura et al. 2009, p. 187, fig. 2-2-33-171; Okumura, Noine \& Ohba 2016, p. 74, figs. $1 \mathrm{E}-\mathrm{G}, 2,5$.

Coelotes towaensis Nishikawa 2009, p.64, fig. 2-1-83; Okumura et al. 2009, p. 187, fig. 2-2-33-172.

Diagnosis. Genital organs of $A$. sanoi are most similar to those of $A$. unicatus. For the differences between the two species, refer to Okumura et al. (2016).

Description. Male: total length 10.0-13.0 mm. Palp (Fig. 1B): for details, refer to Okumura et al. (2016).

Female: total length 11.0-14.0 mm. Epigyne (Fig. 1E): atrium as a longitudinal furrow situated in the central portion of the epigyne, and swollen in both its lateral sides; epigynal teeth short and triangular situated distantly from each other in the lateral sides of the epigyne.

Morphological variations. Intraspecific variations are 


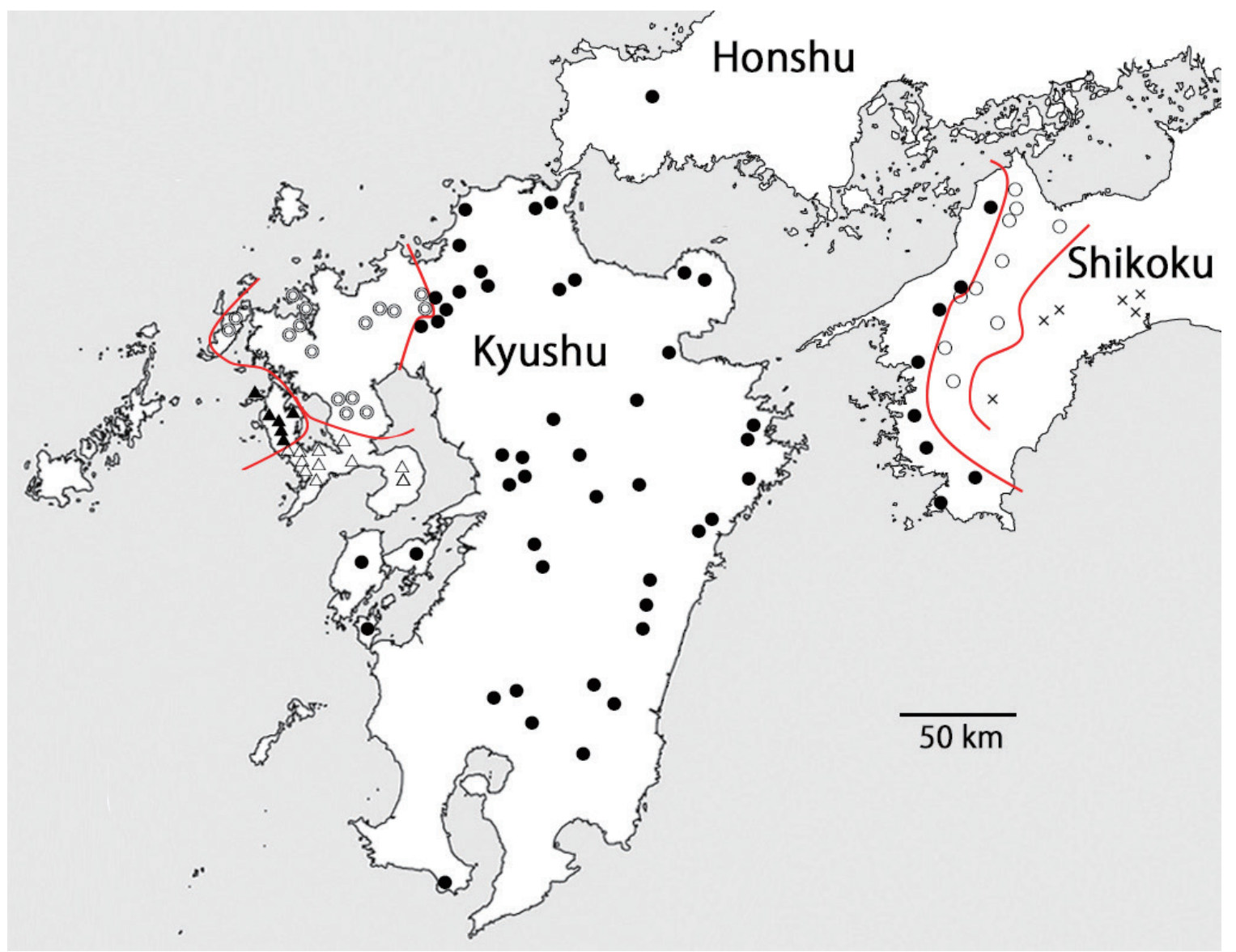

Fig. 3. Distribution of six species of Aeolocoelotes gen. n. in Japan. Closed circles denote A. unicatus (Yaginuma 1977); open circles, A. mohrii (Nishikawa 2009); double circles, A. bifurcatus (Okumura \& Ono 2006); closed triangles, A. saikaiensis (Okumura 2013); open triangles, A. unzenensis (Okumura 2013); crosses, A. sanoi (Nishikawa 2009). Lines show the boundaries of the distribution of each species.

shown in the shape of the epigyne. For details, refer to Okumura et al. (2016).

Distribution. Kochi Prefecture, Japan (Fig. 3).

Aeolocoelotes personatus (Nishikawa 1973) comb. n.

(Figs. 2D, 2H)

Coelotes personatus Nishikawa 1973, p.76, figs. 6-0; Nishikawa 1974, p. 177, figs. 25, 26; Yaginuma 1986, p. 149, fig. 81.7; Chikuni 1989, p. 100, fig. 10; Okumura et al. 2009, p. 184, figs. 2-2-33-154-2-2$33-158$.

Diagnosis. The species can be easily distinguished from other coelotine spiders by the intricately branched conductor of the male palp and because the unique epigyne looks like a mandible of a grasshopper.

Description. Male: total length $9.0-12.0 \mathrm{~mm}$. Palp (Fig. 2D): patellar apophysis almost reduced, but two accessory spines present on the dorsum of the patella; LTA small; RTA short and broad; cymbial furrow short, one-quarter of cymbial length; conductor branched in a complicated manner as follows: (1) sickle apophysis elongated to the tip of the cymbium, (2) linguiform protuberance extended to the medial surface, and (3) large apophysis with deep furrow elongated from the lateral surface to the base of cymbium; embolus thick, strongly crooked, and falling into the deep furrow of the large apophysis situated in the lateral side of the tegulum.

Female: total length 9.0-12.0 mm. Epigyne (Fig. 2H): anterior portion of the epigyne with deep furrow, and short epigynal teeth stemming from the thin plate; posterior portion of the epigyne widely protuberant and brown-colored except for a median line; general overview of the epigyne resembles a mandible of a grasshopper.

Distribution. Japan (Honshu, Shikoku, Kyushu).

Aeolocoelotes bifurcatus (Okumura \& Ono 2006) comb. n. (Figs. 2A, 2E) 
Coelotes bifurcatus Okumura \& Ono, 2006 p. 51, figs. 1-4; Okumura et al. 2009, p. 184, figs. 2-2-33-163-2-2-33-166.

Diagnosis. The genital organs of $A$. bifurcatus are most similar to those of $A$. unzenensis, but are easily distinguished from those of the latter species by the presence of a patellar apophysis in the male palp. In female specimens, the epigyne is entirely brown-colored, and both lateral sides are markedly swollen in A. bifurcatus; by comparison, the epigyne of $A$. unzenensis shows a clear contrast between light and shade, and little swelling.

Description. Male: total length 9.5-11.0 mm. Palp (Fig. 2A): for details, refer to Okumura \& Ono (2006).

Female: total length 11.0-13.5 mm. Epigyne (Fig. 2E): for details, refer to Okumura \& Ono (2006).

Morphological variations. Intraspecific variations were observed in specimens collected from different localities (Fig. 6). In the male palps, there were substantial differences in the thicknesses of the conductor and the lengths of the patellar apophysis. In the epigyne, the positional relation of the epigynal teeth and the development of protuberated portions showed differences.

Distribution. Northwestern Kyushu, Japan (Figs. 3, 6).

Aeolocoelotes unzenensis (Okumura 2013) comb. n. (Figs. 2B, 2F)

Coelotes unzenensis Okumura 2013, p. 87, fig. 1A-D.

Diagnosis. Genital organs of $A$. unzenensis are most similar to those of $A$. bifurcatus. For the differences between the two species, refer to the paragraph on $A$. bifurcatus.

Description. Male: total length 9.0-12.0 mm. Palp (Fig. 2B): for details, refer to Okumura (2013).

Female: total length 10.0-16.0 mm. Epigyne (Fig. 2F): for details, refer to Okumura (2013).

Morphological variations. Intraspecific variations are shown markedly in the shape of the epigyne (Fig. 7). Epigynal teeth are absent in normal specimens, but small processes are present in specimens from an extremely narrow area of Nagasaki City (Fig. 7-1-7-3)

Distribution. Nagasaki Prefecture, Japan (Figs. 3, 7).

Aeolocoelotes saikaiensis (Okumura 2013) comb. n. (Figs. 2C, 2G)

Coelotes saikaiensis Okumura 2013, p. 87, figs. 1E-H.

Diagnosis. Male genital organs of $A$. saikaiensis resemble those of $A$. unzenensis due to the patella that lacks apophysis, but are easily distinguished from those of the latter species by the spoon-shaped median apophysis and the conductor obliquely pointing in the direction of the base of the cymbium (Fig. 2C). Overall differences in the shape of the epigyne make it distinguishable from that other species in the same genus (Figs. 1D-F; 2E-H).
Description. Male: total length 10.0-11.0 mm. Palp (Fig. 2C): for details, refer to Okumura (2013).

Female: total length 10.0-12.0 mm. Epigyne (Fig. 2G): for details, refer to Okumura (2013).

Distribution. Nagasaki Prefecture, Japan (Fig. 3).

Consideration of the importance of morphological characteristics discovered in Aeolocoelotes gen. $n$.

Wang (2002) estimated the phylogeny of 20 genera of the subfamily Coelotinae on the basis of cluster analysis of 31 morphological characteristics; a key to the genera for both sexes was suggested that incorporated the morphology of the genital organs. Wang (2003) also made a key to the species of 10 genera that mainly included species of the genus Draconarius Ovtchinnikov 1999. In the classification of coelotine spiders to date, these characteristics have generally been used. Speciation is likely to have occurred in Aeolocoelotes gen. $\mathrm{n}$. while partial similarities have been retained in various genital parts among each species. The features of this genus suggest that it will be necessary to review existing classifications conducted using limited morphological characteristics as follows.

1. Presence or absence of patellar apophysis

The presence or absence of the patellar apophysis is regarded as an important characteristic for generic diagnosis in males. Wang (2002) suggested that Alloclubionoides Paik 1992 (previously Ambanus) and Inermocoelotes Ovtchinnikov 1999 (previously Eurocoelotes), which have no patellar apophysis, are distinguishable from other genera by this characteristic. The presence or absence of the patellar apophysis is also used as the first identification point of males when classifying species from the genus Draconarius (Wang 2003). As observed here, A. unzenensis and A. saikaiensis also have no patellar apophysis, and these two species share a strict parapatric distribution (Figs. 2B-C, 3). Therefore, they clearly share a phylogeny. In addition, the male palp of $A$. bifurcatus resembles that of $A$. unzenensis, except for the patellar apophysis (Figs. 2A-B); these two species also share a parapatric distribution (Fig. 3). However, the latter two species had previously been considered to differ in their phylogeny on the basis of the presence or absence of the patellar apophysis. Given the molecular analysis of $A$. unzenensis, $A$. saikaiensis, and $A$. bifurcatus, characterizing the overall similarity of the male palp is required, rather than only characterizing based on the presence or absence of the patellar apophysis.

2. Presence or absence of epigynal teeth

The presence or absence of epigynal teeth has been used as the first divergence of the key to genera in female coelotine spiders (Wang 2002) as well as the classification of females in the species group of the genus Draconarius (Wang 2003). This would suggest that the presence or absence of epigynal teeth is extremely important for the classification of coelotine spiders. However, species with and without epigynal teeth are intermingled in the genera Coelotes and Draconarius (Wang \& Jäger 2010). This confusion in clas- 


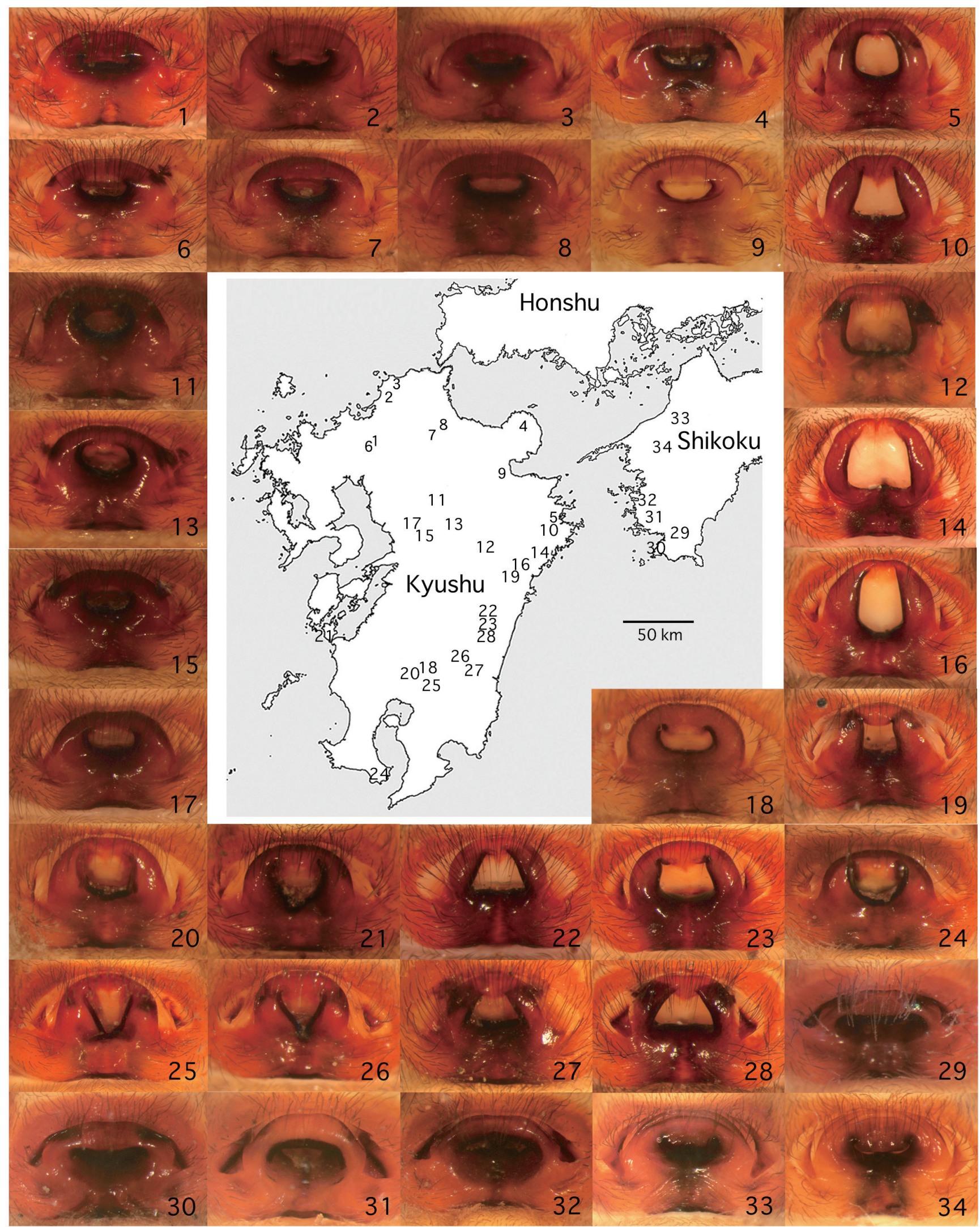

Fig. 4. Geographic variations of the epigyne of Aeolocoelotes unicatus (Yaginuma 1977). The photo numbers correspond to the numbers indicating the collection localities on the map. 

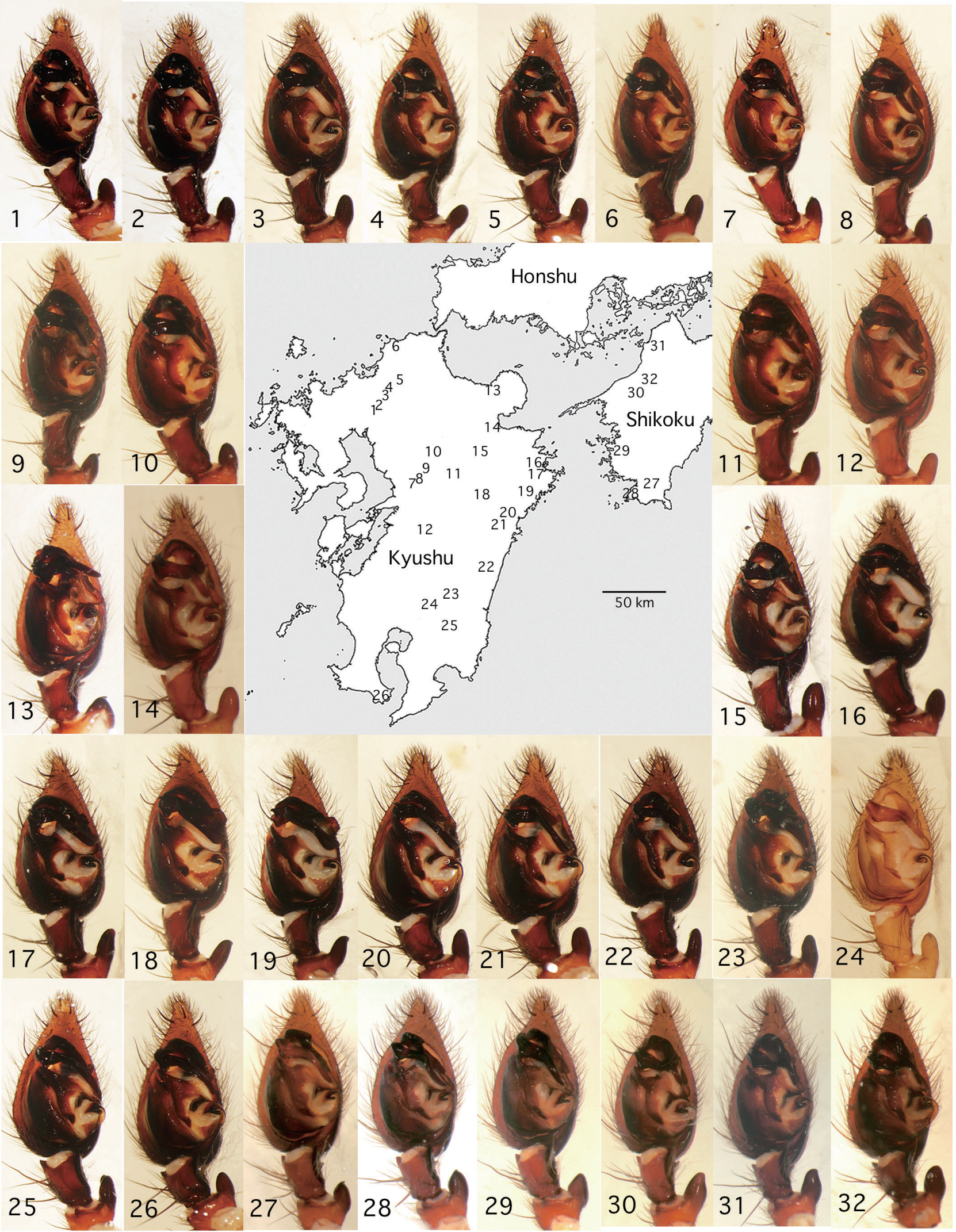

Fig. 5. Morphological similarity of the male palp of Aeolocoelotes unicatus (Yaginuma 1977). The photo numbers correspond to the numbers indicating the collection localities on the map. 

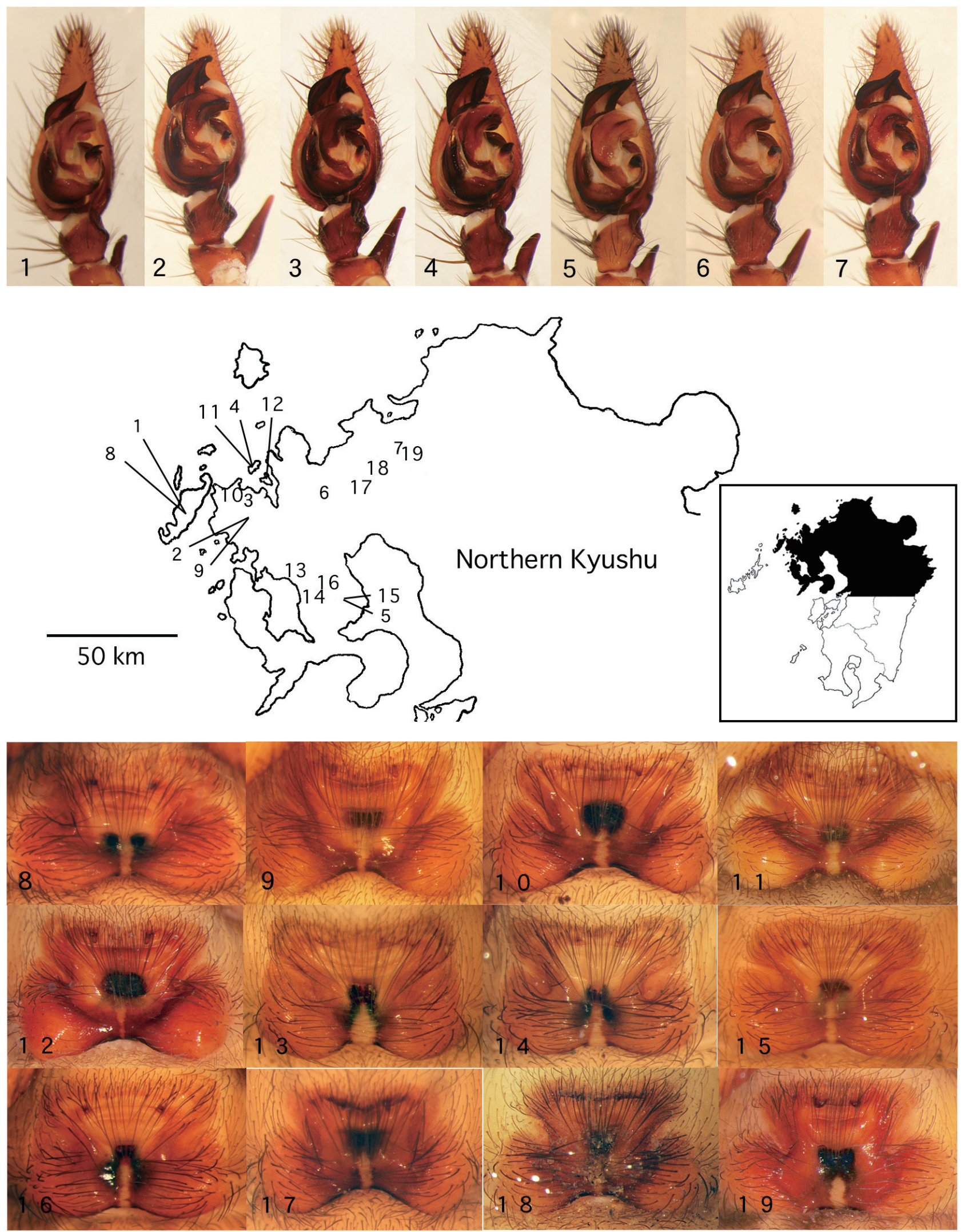

Fig. 6. Geographic variations of the male palp and the epigyne in Aeolocoelotes bifurcatus (Okumura \& Ono 2006). The photo numbers correspond to the numbers indicating the collection localities on the map. 

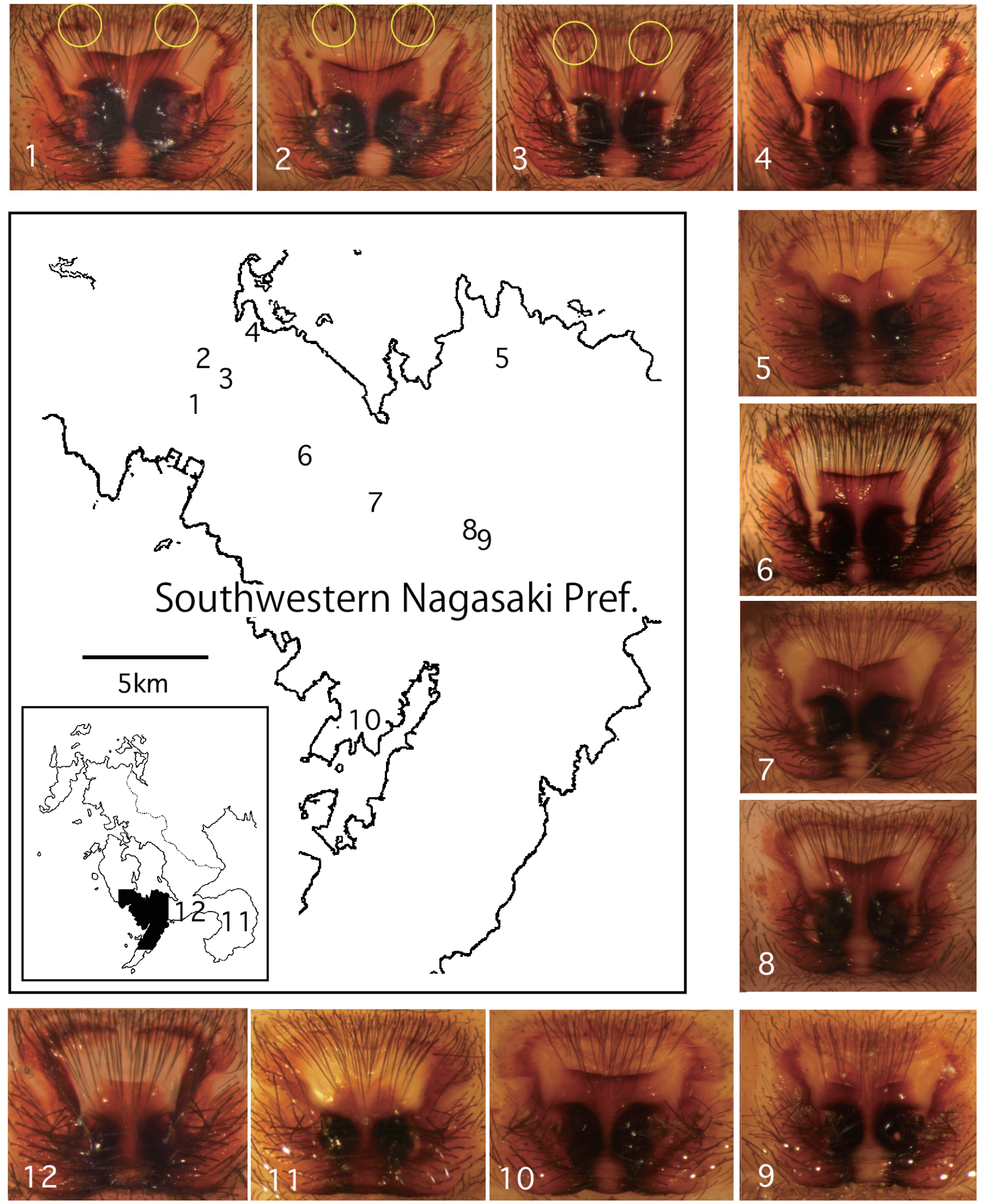

Fig. 7. Geographic variations of the epigyne of Aeolocoelotes unzenensis (Okumura 2013). The photo numbers correspond to the numbers indicating the collection localities on the map. Tiny epigynal teeth are shown in the photo 1-3 (within the circles). 
sification by morphology is considered to have been brought about by temporary assignments to these two genera (Wang 2003; Wang \& Jäger 2007, 2010). Thus, a taxonomic revision in Coelotes and Draconarius was required. In this study, specimens with small epigynal teeth occurred in $A$. unzenensis, and they were collected from the northern part of Nagasaki City (Figs. 7-1-7-3). This is a rare case of intraspecific variation, but it indicates that the presence or absence of epigynal teeth is not as stable a characteristic as it was previously considered to be. Indeed, such variation can occur even within conspecific specimens.

3. Shape of the epigynal atrium

The shape of the epigynal atrium has also been used as the basis for classification in female coelotine spiders (Wang 2002, 2003; Wang \& Jäger 2007, 2008). Wang (2002) divided the atrium size into two categories, namely large and small, for the classification of the coelotine genera. It was suggested that genera with large atrium include Orumcekia Koçak \& Kemal 2008 (previously Coronilla), Alloclubionoides (previously Ambanus), and Robusticoelotes Wang 2002; however, the atrium of these three genera is larger than that of Femoracoelotes Wang 2002, Tonsilla Wang \& Yin 1992, Pireneitega Kishida 1955 (previously Paracoelotes), and Draconarius. Remarkable geographic variation occurs in the shape and size of the epigynal atrium of $A$. unicatus, and this variation is continuous (Fig. 4). However, geographic variation in the shape of the male palp is rarely observed (Fig. 5 ), and judging from past results of molecular phylogenetic analysis (Okumura et al. 2016), these female specimens are regarded as conspecifics.

Curticoelotes gen. n.

(Japanese name: Hirado-yachigumo-zoku)

Type species. Coelotes hiradoensis Okumura \& Ono 2006 (preserved in the collection of the Tsukuba Research Department, the National Museum of Nature and Science, Tokyo, NSMT-Ar 6781).

Etymology. The generic name is a compound noun derived from the Latin curtus "short" and the existing generic name Coelotes, and it refers to the short cymbium of the male palp. The gender is masculine.

Diagnosis. By comparison with other genera that have two retromarginal teeth on their chelicerae, this new genus is characterized by a short cymbium and a genital bulb that widely covers the lower surface of the cymbium.

Composition. Two species groups consisting of six species as follows:

\section{Species group of Curticoelotes hiradoensis}

Curticoelotes hiradoensis (Okumura \& Ono 2006) comb. n.

Curticoelotes sawadai (Nishikawa 2009) comb. $\mathrm{n}$.

Curticoelotes taurus (Nishikawa 2009) comb. $\mathrm{n}$.

Curticoelotes oxyacanthus (Okumura 2013) comb. $\mathrm{n}$.

Species group of Curticoelotes hamamurai

Curticoelotes hamamurai (Yaginuma 1967) comb. $\mathrm{n}$.

Curticoelotes kintaroi (Nishikawa 1983) comb. $\mathrm{n}$.
Description. Small- to medium-sized coelotine spiders, $4.5-11.0 \mathrm{~mm}$ in length. Cheliceral promargin with three teeth, retromargin with two. Leg formula IV-I-II-III. Carapace yellowish brown with indistinct radial flecks; dorsum of abdomen grayish brown with yellowish brown chevrons, and venter yellowish brown without flecks; sternum yellowish brown; chelicerae, maxillae, and labium brown; legs yellowish brown without ring flecks.

Male. Palp (Figs. 8A-D, 9A-B): cymbium short and genital bulb covering the lower surface of cymbium widely; patellar apophysis and RTA present; LTA absent; conductor various shapes for each species; CDA present; median apophysis spoon-shaped; embolus thick in C. kintaroi, but thin and flagelliform in other species.

Female. Epigyne and internal genitalia (Figs. 8E-L, 9CF). (1) Species group of Curticoelotes hiradoensis: anterolateral portion with thin sclerotized flames on both sides; epigynal teeth slender and elongated to the central portion of the epigyne; spermathecae globular and distant from each other; copulatory duct strongly convoluted with differing development for each species. (2) Species group of Curticoelotes hamamurai: epigyne almost oval-shaped; epigynal teeth acuminate, and conglutinated with thin plate in anterior portion; spermathecae globular and distant from each other in C. hamamurai, but close to each other in C. kintaroi.

Distribution. Japan (Honshu, Kyushu).

Remarks. Curticoelotes gen. n. is divided into the two species groups as a result of molecular analysis. The two species groups are morphologically related by the short cymbium of the male palp and the globular spermatheca of the female internal genitalia (Figs. 8A-D, I-L; 9A-B, C-F). Therefore, the two groups are considered to be closely related. C. sawadai comb. n. and C. taurus comb. n. were not examined using molecular analysis in this study; however, it is clear that these species share a phylogenetic relationship with $C$. hiradoensis and $C$. oxyacanthus by the similarity in their genital organs for both sexes, e.g., the short cymbium of the male palp, and the thin epigynal teeth and globular spermathecae of the female internal genitalia (Fig. 8). Therefore, taxonomic revisions were also conducted for $C$. sawadai comb. n. and C. taurus comb. n.

Curticoelotes hiradoensis (Okumura \& Ono 2006) comb. n. (Figs. 8A, 8E, 8I)

Coelotes hiradoensis Okumura \& Ono 2006, p.53, figs. 5-8; Okumura et al. 2009, p. 188, figs. 2-2-33-173-2-2-33-176.

Diagnosis. C. hiradoensis can be distinguished from the other three species in its species group by the shape of the conductor, length and condition of separation of the epigynal teeth, and development of the copulatory ducts. The genital organs of C. hiradoensis are most similar to those of C. oxyacanthus. For the differences between the two species, refer to the description of C. oxyacanthus (Okumura 2013).

Description. Male: total length 5.5-6.5 mm. Palp (Fig. 

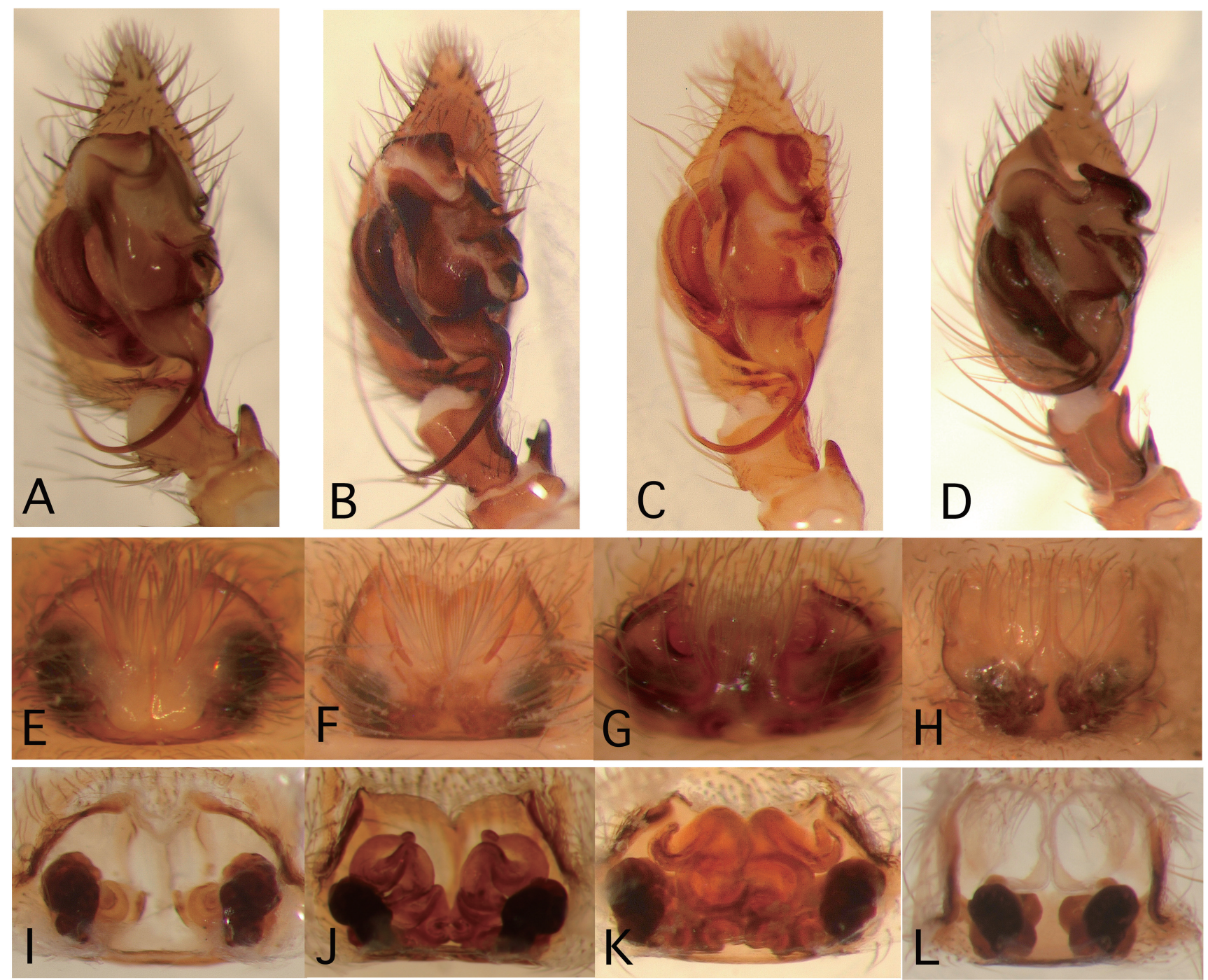

Fig. 8. Comparison of genitalic characters of four species of Curticoelotes gen. n. (species group of C. hiradoensis) from Japan: A, E, I, C. hiradoensis (Okumura \& Ono 2006), B, F, J, C. oxyacanthus (Okumura 2013), C, G, K, C. taurus (Nishikawa 2009), D, H, L, C. sawadai (Nishikawa 2009). A, B, C, D, ventral views of male palp; E, F, G, H, ventral views of epigyne; I, J, K. L, internal female genitalia.

8A): for details refer, to Okumura \& Ono (2006).

Female: total length $6.0-7.5 \mathrm{~mm}$. Epigyne and internal genitalia (Figs. 8E, 8I): for details, refer to Okumura \& Ono (2006).

Distribution. Nagasaki Prefecture, Japan (Hirado Island, Uku Island).

Curticoelotes sawadai (Nishikawa 2009) comb. n. (Figs. 8D, 8H, 8L)

Coelotes sawadai Nishikawa 2009, p. 65, figs. 2-1-N-84-2-1-N-87; Okumura et al. 2009, p. 187, figs. 2-2-33-177-2-2-33-179.

Diagnosis. Males of C. sawadai can be distinguished from males of the other three species in its species group by the smoothly bent conductor of the palp. Females can be distinguished by epigynal teeth that are arcuately elongated to the central portion and by spermathecae that are close to each other.

Description. Male: total length 5.5-6.5 mm. Palp (Fig. 8D): for details, refer to Nishikawa (2009).

Female: total length $6.0-7.0 \mathrm{~mm}$. Epigyne and internal genitalia (Figs. 8H, 9L): for details, refer to Nishikawa (2009).

Distribution. Japan (Honshu, Kyushu).

Curticoelotes taurus (Nishikawa 2009) comb. n.

(Figs. 8C, 8G, 8K) 
Coelotes taurus Nishikawa 2009, p. 65, figs. 2-1-N-88-2-1-N-91; Okumura et al. 2009, p. 187, figs. 2-2-33-180-2-2-33-182.

Diagnosis. Males of $C$. taurus can be distinguished from males of the other three species in its species group by the undeveloped conductor of the palp. Females can be distinguished by short epigynal teeth and strongly convoluted copulatory ducts.

Description. Male: total length 4.5-6.0 mm. Palp (Fig. 8C): for details, refer to Nishikawa (2009).

Female: total length 4.5-6.0 mm. Epigyne and internal genitalia (Figs. 8G, 8K): for details, refer to Nishikawa (2009).

Distribution. Western Japan (Honshu).

Curticoelotes oxyacanthus (Okumura 2013) comb. n. (Figs. 8B, 8F, 8J)

Coelotes oxyacanthus Okumura 2013, p. 92, fig. 5A-D

Diagnosis. C. oxyacanthus can be distinguished from the other three species in its species group by the small and pointed conductor of the male palp, and by long and acute epigynal teeth. The genital organs of $C$. oxyacanthus are most similar to those of $C$. hiradoensis. For the differences between the two species, refer to the description of $C$. oxyacanthus (Okumura 2013).

Description. Male: total length 5.5-6.5 mm. Palp (Fig. 8B): for details, refer to Okumura (2013).

Female: total length $6.0-7.5 \mathrm{~mm}$. Epigyne and internal genitalia (Figs. 8F, 8J): for details, refer to Okumura (2013).

Distribution. Nagasaki Prefecture, Japan (Goto Islands).

Curticoelotes hamamurai (Yaginuma 1967) comb. n. (Figs. 9A, 9C, 9E)

Coelotes hamamurai Yaginuma 1967, p. 99, fig. 3u-w; Yaginuma 1986, p. 149, fig. 81-5; Nishikawa 1974, p. 177, figs. 23, 24; Shinkai 1978 , p. 95 , figs. 35 , 36; Okumura et al. 2009, p. 184, figs. 2-2-33145-2-2-33-148.

Diagnosis. C. hamamurai can be distinguished from the other species in its species group, $C$. kintaroi, by the broad conductor and thin embolus of the male palp, and by the spermathecae situated in the posterior portion of the epigyne being distant from each other.

Description. Male: total length $6.5-8.5 \mathrm{~mm}$. Palp (Fig. 9A): patellar apophysis short, situated on dorsum; LTA small and conglutinated to RTA; RTA slender; cymbial furrow about one-half of cymbial length; conductor short and broad; median apophysis spoon-shaped; embolus flagelliform, and arc-shaped in anterior portion of the conductor.

Female: total length 7.0-11.0 mm. Epigyne and internal genitalia (Figs. 9C, 9E): epigyne wide horizontally; short epigynal teeth stem from thin plate in anterior portion of epigyne; long atrial slit present in central portion of epigyne; spermathecae globular, distant from each other, and connect- ed with the copulatory ducts in the anterior portion by bent tubes.

Distribution. Northern and eastern Japan (Honshu).

Curticoelotes kintaroi (Nishikawa 1983) comb. n. (Figs. 9B, 9D, 9F)

Coelotes kintaroi Nishikawa 1983, p. 128, figs. 7-12; Yaginuma 1986, p. 151, fig. 81-6; Okumura et al. 2009, p. 184, figs. 2-2-33-149-2-233-153.

Diagnosis. The male of $C$. kintaroi has a remarkable protrusion that elongates to the patella in the dorsum of cymbium. Therefore, the species can be distinguished from all other coelotine species by this characteristic. The epigyne resembles that of $C$. hamamurai, but the long atrial slit is not found in $C$. kintaroi.

Description. Male: total length 8.0-10.0 mm. Palp (Fig. 9B): patellar apophysis short; LTA small and conglutinated to RTA; RTA slender; thick and short process situated in dorsum of tibia; cymbial furrow one-third of cymbial length; large protrusion elongates to the patella in the dorsum of the cymbium; conductor rod-shaped and bent inwards; CDA broad and inward; median apophysis spoon-shaped; embolus thick overall.

Female: total length 8.5-11.0 mm. Epigyne and internal genitalia (Figs. 9D, 9F): epigyne elliptical-shaped horizontally; short epigynal teeth stem from thin plate in anterior portion of the epigyne; saucer-shaped dark portion appears in the central part of the epigyne; spermathecae almost globular, close to each other, and in the posteromedian portion.

Distribution. Northern Japan (Honshu).

Griseidraconarius gen. n. (Japanese name: Usuiro-yachigumo-zoku)

Type species. Coelotes decolor Nishikawa 1973 (preserved in the collection of the Osaka Museum of Natural History).

Etymology. The generic name is a compound noun derived from the Latin griseus "gray" and the existing generic name Draconarius, and it refers to the pale-colored body. The gender is masculine.

Diagnosis. The new genus can be distinguished from almost all other Japanese coelotine species by its pale-colored body. The male can be distinguished from males of other genera by the broad and extremely bent conductor in the palp. The female can be distinguished by tiny epigynal teeth situated on the anteromedian or central portion of the epigyne, and by small spermathecae consisting of a few globular bulbs.

Composition. Three species:

Griseidraconarius decolor (Nishikawa 1973) comb. n. Griseidraconarius akakinaensis (Shimojana 2000) comb. n. Griseidraconarius iriei (Okumura 2013) comb. n.

Description. Small- to large-sized coelotine spiders, 6.0- 


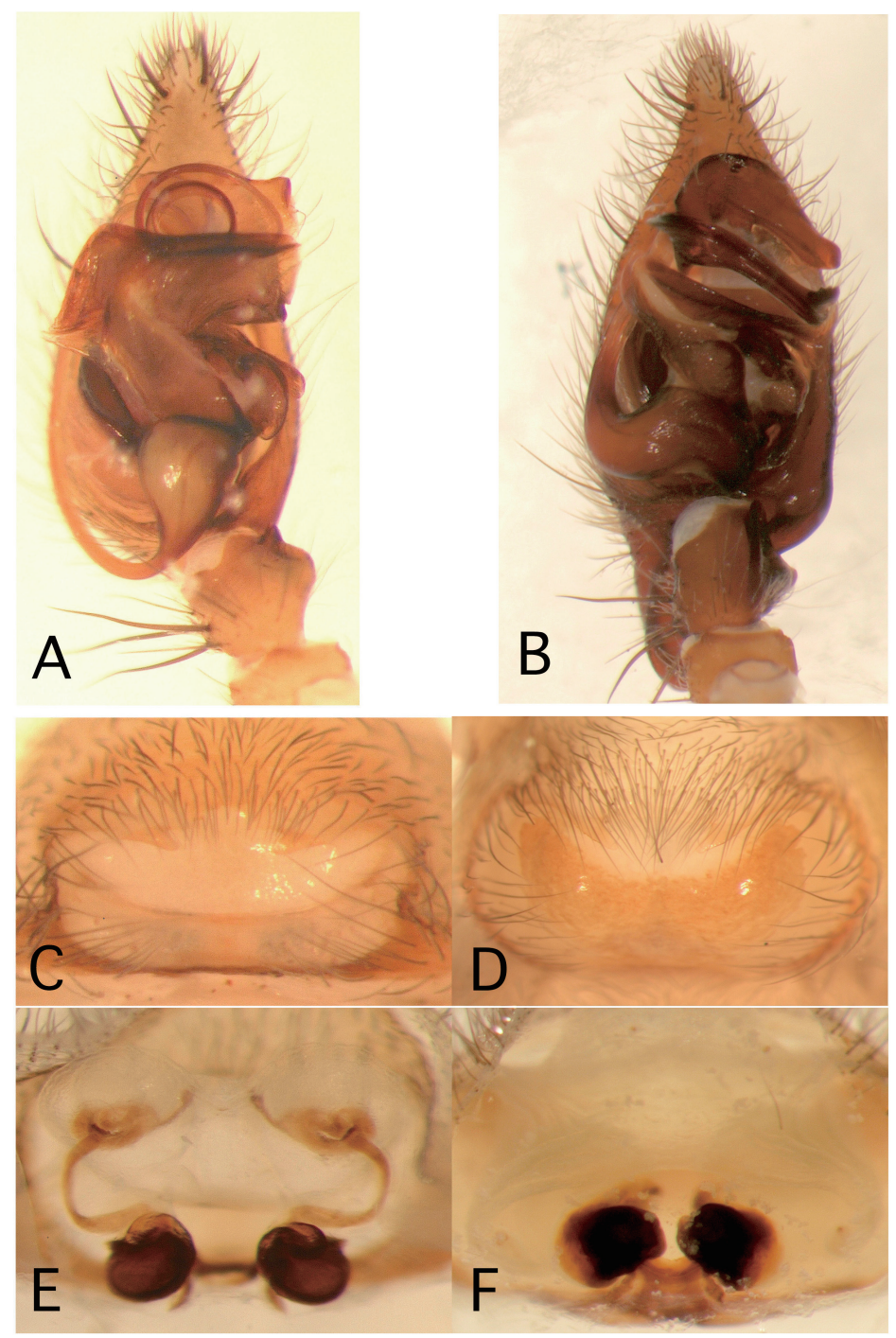

Fig. 9. Comparison of genitalic characters of two species of Curticoelotes gen. n. (species group of C. hamamurai) from Japan: A, C, E, C. hamamurai (Yaginuma 1967), B, D, F, C. kintaroi (Nishikawa 1983). A, B, ventral views of male palp; C, D, ventral views of epigyne; E, F, internal female genitalia.

$13.0 \mathrm{~mm}$ in length. Cheliceral promargin with three teeth, retromargin with two. Leg formula IV-I-II-III. Carapace yellowish brown or gray with indistinct radial flecks; dorsum of abdomen pale gray with indistinct chevrons, and venter pale gray without flecks; sternum yellowish brown or gray; chelicerae, maxillae, and labium brown; legs yellowish brown or gray without ring flecks.

Male. Palp (Figs. 10A-C): patellar apophysis short and small process present in dorsum of the patella; LTA absent; RTA broad; conductor broad and spiraled; median apophysis spoon-shaped; embolus thick and stout.

Female. Epigyne and internal genitalia (Figs. 10D-I): tiny epigynal teeth present in the central or anteromedian portion of the epigyne; spermathecae consisting of two or three small bulbs situated in the posterior portion of the epigyne and close to each other; copulatory ducts variously shaped for each species.

Distribution. Japan (Honshu, Shikoku, Kyushu, Ryukyu Islands).

Griseidraconarius decolor (Nishikawa 1973) comb. n. (Figs. 10A, 10D, 10G)

Coelotes decolor Nishikawa 1973, p.75, figs. 1-5; Nishikawa 1974, p. 178, figs 27, 28; Shinkai 1978, p. 95, figs. 33, 34; Yaginuma 1986, p. 151, fig. 82-9; Chikuni 1989, p. 102, fig. 17; Okumura et al. 2009, p. 187, figs. 2-2-33-183-2-2-33-187; Wang \& Ono 2010, p.594, figs. 1, 2. 


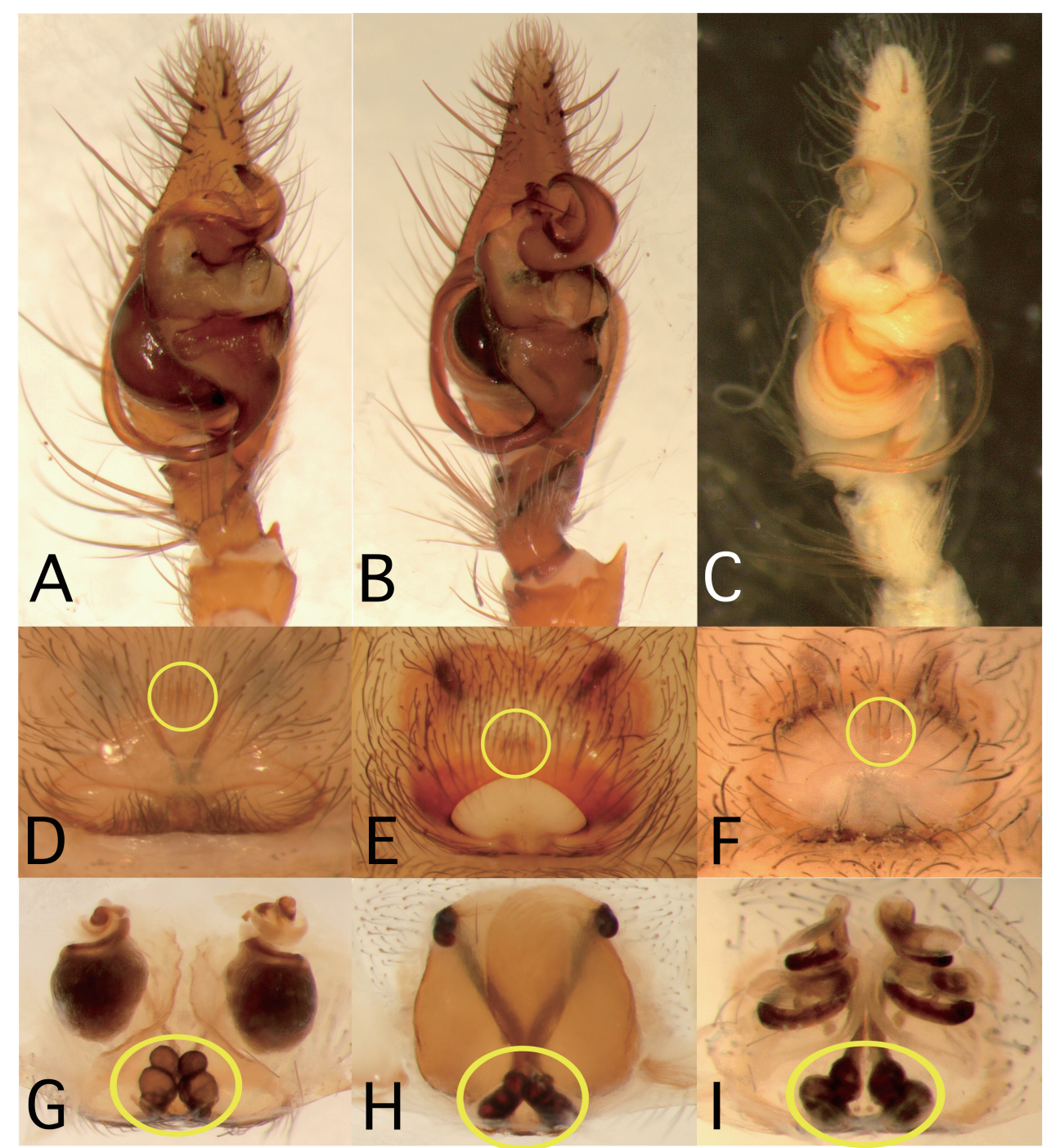

Fig. 10. Comparison of genitalic characters of three species of Griseidraconarius gen n. from Japan: A, D, G, G. decolor (Nishikawa 1973), B, E, H, G. iriei (Okumura 2013), C, F, I, G. akakinaensis (Shimojana 2000). A, B, C, ventral views of male palp; D, E, F, ventral views of epigyne, within the circles, tiny epigynal teeth; G, H, I, internal female genitalia, within the circles, spermathecae consisting of a few small bulbs.

Diagnosis. The male of $G$. decolor can be distinguished from males of the other two species by the form of the conductor, base of the embolus, and development of the patellar apophysis in the palp. The degree of curvature of the conductor is the highest in $G$. iriei. The base of the embolus of $G$. iriei becomes thin and curved toward the inside; $G$. decolor and G. akakinaensis do not possess this characteristic. The patellar apophysis is present in $G$. decolor and G. iriei, but undeveloped in G. akakinaensis. The female can be distinguished by the horizontally-long epigyne, and by the large and globular bulbs in the combining site between the spermathecae and copulatory ducts.
Description. Male: total length $6.0-11.0 \mathrm{~mm}$. Palp (Fig. 10A): patellar apophysis small; LTA absent; RTA small; cymbial furrow about one-half of cymbial length; conductor curves in the direction of the tip of the cymbium; embolus somewhat thick.

Female: total length $6.0-12.0 \mathrm{~mm}$. Epigyne and internal genitalia (Figs. 10D, 10G): epigyne horizontally long; epigynal teeth minute, situated in the anteromedian portion of the epigyne; atrial slit present in the central portion of the epigyne; spermathecae consisting of a few globular bulbs and close to each other; large bulbs conglutinating with the copulatory ducts present in the anterolateral portion. 
Distribution. Japan (Honshu, Shikoku, Kyushu).

Remark. In the figures showing the male palp in the original description, the genital bulb turns clockwise, so it is not shown in its normal condition. Therefore, it is somewhat difficult to identify accurately.

Griseidraconarius akakinaensis (Shimojana 2000) comb. n. (Figs. 10C, 10F, 10I)

Coelotes akakinaensis Shimojana 2000, p. 200, figs 36-43; Shimojana 2003, p. 28, 29, figs. 2-24; Okumura et al. 2009, p. 187, figs. 2-233-306-2-2-33-311.

Diagnosis. For differences in the male, refer to the diagnosis of G. decolor. The female can be distinguished from females of the other two species by the oval-shaped epigyne, and by the elongated spiral spermathecae in the anterolateral portion of the internal genitalia.

Description. Male: total length $10.0-12.0 \mathrm{~mm}$. Palp (Fig. 10C): patellar apophysis small; LTA absent; RTA broad; cymbial furrow about one-half of cymbial length; conductor broad, spiraled with one loop; base of the embolus thick, and deeply grooved in lateral view.

Female: total length 10.0-13.0 mm. Epigyne and internal genitalia (Figs. 10F, 10I): epigyne oval-shaped; epigynal teeth minute, situated in the anteromedian portion of the epigyne; atrial slit indistinct; spermathecae consisting of a few globular bulbs, close to each other, and elongated spirally to the anterior portion.

Distribution. Kagoshima Pref., Japan (Amami-oshima Island).

Remark. In the figures showing the male palp in the original description, the genital bulb turns counterclockwise, so it is not shown in its normal condition. Therefore, it is somewhat difficult to identify accurately.

Griseidraconarius iriei (Okumura 2013) comb. n. (Figs. 10B, 10E, 10H)

Coelotes iriei Okumura 2013, p. 92, fig. 3E-H.

Diagnosis. For the differences in the male, refer to the diagnosis of $G$. decolor. The female can be distinguished from females of the other two species by the deeply-hollowed atrium in the posterior portion of the epigyne, linearly-elongated spermathecae, and large copulatory ducts.

Description. Male: total length $10.0-12.0 \mathrm{~mm}$. Palp (Fig. 10B): for details, refer to Okumura (2013).

Female: total length $10.0-13.0 \mathrm{~mm}$. Epigyne and internal genitalia (Figs. 10E, 10H): for details, refer to Okumura (2013).

Distribution. Southern Kyushu, Japan.

\section{Acknowledgments}

For providing the specimens used in this study, I am grateful to Mr. Teruo Irie (Kumamoto), Dr. Yoh Ihara (Hiroshima), and Mr. Koichi Nojima (Okayama). I wish to express my sincere thanks to Mr. Ka- zuyuki Honki and Dr. Shin-ya Ohba (Nagasaki University) for helping with the molecular analysis. My heartfelt thanks are also due to Dr. Hirotugu Ono (National Museum of Nature and Science) for providing practical advice. I would like to thank Enago (www.enago.jp) for the English language review.

\section{References}

Bi, K. R., Zhou, K. Y. \& Song, D.-X. 2005. Phylogenetic position of the spider subfamily Coelotinae (Araneae) inferred from nuclear rDNA gene sequences. Acta Zool. Sin., 51: 521-525.

Chen, L., Li, S. \& Zhao, Z. 2015a. Five new Platocoelotes species (Araneae, Agelenidae) from caves in southern China. Zookeys, 512: $1-18$.

Chen, L., Li, S. \& Zhao, Z. 2015b. A new genus of Coelotinae (Araneae, Agelenidae) from southern China. Zookeys, 541: 41-56.

Chen, L., Zhao, Z. \& Li, S. 2016. Sinocoelotes gen. n., a new genus of the subfamily Coelotinae (Araneae, Agelenidae) from Southeast Asia. Zookeys, 614: 51-86.

Chikuni, Y. 1989. Pictorical Encyclopedia of Spiders in Japan. Kaiseisha, Tokyo, 310pp. (In Japanese)

Irie, T. 1985. The spiders in the Amakusa Islands, Kumamoto Prefecture. Calanus, 9: 1-20. (In Japanese with English summary)

Koch, C. L. 1837. Übersicht des Arachnidensystems, Heft 1. 39 pp. C. H. Zeh'sche Buchhandlung, Nürunberg.

Li. B., Zhao, Z., Zhang, C. \& Li, S. 2018a. Sinodraconarius gen. n., a new genus of Coelotinae spiders from Southwest China (Araneae, Agelenidae). Zookeys, 770: 117-135.

Li, B., Zhao, Z., Chen, H., Wu, Z., Zhang, C. \& Li, S. 2018b. Guilotes, a new genus of Coelotinae spiders from Guangxi Zhuang Autonomous Region, China (Araneae, Agelenidae). ZooKeys, 802: 1-17.

Li. B., Zhao, Z., Zhang, C. \& Li, S. 2018c. Nuconarius gen. n. and Hengconarius gen. n., two new genera of Coelotinae (Araneae, Agelenidae) spiders from Southwest China. Zootaxa, 4457: 237-262.

Li, B., Zhao, Z., Chen, Y. X., Chen, H. F., Wu, Z. Y. \& Li, S. Q. 2019a. Vappolotes, a new genus of coelotine spiders (Araneae, Agelenidae) from Guizhou, China. Zootaxa, 4701: 434-442.

Li, B., Zhao, Z., Zhang, C. \& Li, S. 2019b. Troglocoelotes gen. n., a new genus of Coelotinae spiders (Araneae, Agelenidae) from caves in South China. Zootaxa, 4554: 219-238.

Miller, J. A., Carmichael, A., Ramirez, M. J., Spagna, J. C., Haddad, C. R., Rezác, M., Johannesen, J., Král, J., Wang X. P. \& Griswold, C. E. 2010. Phylogeny of entelegyne spiders: affinities of the family Penestomidae (NEW RANK), generic phylogeny of Eresidae, and asymmetric rates of change in spinning organ evolution (Araneae, Araneoidea, Entelegynae). Mol. Phylogenet. Evol., 55: 786-804.

Nishikawa, Y. 1973. Two new spiders of the genus Coelotes (Araneae: Agelenidae) from Japan. Fac. Let. Otemon Gakuin Univ., 7: 75-81.

Nishikawa, Y. 1974. Japanese spiders of the genus Coelotes (Araneae: Agelenidae). Fac. Let. Otemon Gakuin Univ., 8: 173-182.

Nishikawa, Y. 1983. Spiders of the genus Coelotes (Araneae, Agelenidae) from the mountains of the Tôhoku District, northeast Japan. Mem. Natl. Sci. Mus. Tokyo 16: 123-136.

Nishikawa, Y. 2009. A new genus and 44 new species of the family Coelotidae (Arachnidae, Araneae) from Japan. In: Ono, H. (ed.) The spiders of Japan with keys to the families and genera and illustrations of the species. Tokai Univ. Press Kanagawa, pp. 51-70.

Okumura, K. 2007. Three new species of the subfamily Coelotinae (Araneae: Amaurobiidae) from Kyushu, Japan. Acta Arachnol., 56: 85-90.

Okumura, K. 2009. Variations of the number of retromarginal teeth on chelicerae in Coelotid spiders from Kyushu district, Japan. Trans. Nagasaki Biol. Soc., 66: 23-28. (In Japanese with English summary)

Okumura, K. 2010. First description of the male of Platocoelotes uenoi (Yamaguchi \& Yaginuma, 1971), n. comb. and a new record of Draconarius coreanus (Paik \& Yaginuma 1969) (Araneae: Coelotidae) from Kyushu, Japan. Acta Arachnol., 59: 5-7. 
Okumura, K. 2013. Seven new species of spiders of the subfamily Coelotinae (Araneae: Agelenidae) from Kyushu, Japan. Species Diversity, 18: 87-97.

Okumura, K. 2017. Dichodactylus gen. nov. (Araneae: Agelenidae: Coelotinae) from Japan. Species Diversity, 22: 29-36.

Okumura, K. 2019. Two new species of the subfamily Coelotinae (Araneae: Agelenidae) from Central Honshu, Japan. Arachnology, 18(3): 291-295.

Okumura, K \& Ono, H. 2006. Two new species and a new synonymy of the subfamily Coelotinae (Araneae: Amaurobiidae) from Kyushu, Japan. Acta Arachnol., 55: 51-58.

Okumura, K., Nishikawa, Y., Shimojana, M. \& Ono, H. 2009. Coelotidae. In: Ono, H. (ed.) The spiders of Japan with keys to the families and genera and illustrations of the species. Tokai Univ. Press Kanagawa, pp. 174-205. (In Japanese)

Okumura, K., Ono, H. \& Nishikawa, Y. 2011. Two new species of the genus Tegecoelotes (Araneae: Agelenidae) from Chubu and Chugoku Districts, Honshu, Japan. Acta Arachnol., 60: 47-50.

Okumura, K., Noine, M. \& Ohba, S. 2016. A new synonymy of the species group of Coelotes unicatus Yaginuma 1977, with a first description of the male of Coelotes sanoi Nishikawa 2009 (Araneae: Agelenidae) from Shikoku District, Japan. Acta Arachnol., 65: $71-76$.

Okumura, K., Koike, N. \& Nakano, T. 2017. Revision of the taxonomic status of two coelotine species (Araneae: Agelenidae) from Japan. Acta Arachnol., 66: 73-78.

Okumura, K., Honki, K. \& Ohba, S. 2019. Notes on several Japanese species of Iwogumoa and Coelotes (Araneae: Agelenidae: Coelotinae). Species Diversity, 24(2): 247-252.

Ono, H. 2008. Five new spiders of the families Dictynidae, Cybaeidae, Coelotidae and Ctenidae (Arachnida, Araneae) from Japan. Bull. Natl. Mus. Nat. Sci. Ser. A, 34: 157-171.

Pickard-Cambridge, F. O. 1893. Handbook to the study of British spiders (Drassidae and Agelenidae). British Naturalist (Supplement), 3: $117-170$.

Shimojana, M. 2000a. Description of eleven new species of the genus Coelotes (Araneae: Amaurobiidae) from the Ryukyu Islands, Japan. Acta Arachnol., 49: 165-189.

Shimojana, M. 2000b. Description of seven new species of the genus Coelotes (Arachnida: Araneae: Amaurobiidae) from the Amami and the Tokara Islands, Japan. Acta Arachnol., 49: 191-204.

Shimojana, M. 2003. Geographical distribution and speciation of the Coelotine spiders (Araneae, Amaurobiidae) in the Ryukyu Islands. Doctoral thesis, Tohoku University, 300pp. (In Japanese)

Shimojana, M \& Nishihira, M. 2000. A new cave-dwelling eyeless spider of the genus Coelotes (Araneae: Amaurobiidae) from Okinawa Island, the Ryukyu Islands, Japan, with notes on possible parthenogenesis. Acta Arachnol., 49: 29-40.

Shinkai, E. 1978. Spiders of Hachioji City, Tokyo -List and Distribution. Memoirs of the Education Institute for Private Schools in Japan, 56: 79-109. (In Japanese)

Spagna, J. C. \& Gillespie, R. G. 2008. More data, fewer shifts: molecular insights into the evolution of spinning apparatus in non-orb- weaving spiders. Mol. Phylogenet. Evol., 46: 347-368.

Vandergast, A. G., Gillespie, R. G., \& Roderick, G. K. 2004. Influence of volcanic activity on the population genetic structure of Hawaiian Tetragnatha spiders: fragmentation, rapid population growth and the potential for accelerated evolution. Mol. Ecol., 13: 1729-1743.

Wang, X. P. 2002. A generic-level revision of the spider subfamily Coelotinae (Araneae, Amaurobiidae). Bull. Am. Mus. Nat. Hist., 269: 1-150.

Wang, X. P. 2003. Species revision of the coelotinae spider genera Bifidocoelotes, Coronilla, Draconarius, Femoracoelotes, Leptocoelotes, Longicoelotes, Platocoelotes, Spiricoelotes, Tegecoelotes, and Tonsilla (Araneae: Amaurobiidae). Proc. Calif. Acad. Sci., 54: 499-662.

Wang, X. P. \& Jäger, P. 2007. A revision of some spiders of the subfamily Coelotinae F. O. Pickard-Cambridge 1898 from China: transfers, synonymies, and new species (Arachnida, Araneae, Amaurobiidae). Senck. Boil., 87: 23-49.

Wang, X. P. \& Jäger, P. 2008. First record of the subfamily Coelotinae in Laos, with review of Coelotinae embolus morphology and description of seven new species from Laos and Vietnam (Araneae, Amaurobiidae). J. Nat. Hist., 42: 2277-2304.

Wang, X. P. \& Jäger, P. 2010. A review of Coelotine epigynal teeth morphology, with descriptions of two species from China (Araneae: Amaurobiidae). J. Nat. Hist., 44: 1165-1187.

Wang, X. P. \& Ono, H. 2010. Notes on two coelotine spiders from Japan (Araneae: Agelenidae). J. Arachnol., 38: 592-595.

World Spider Catalog. 2020. World Spider Catalog. Natural History Museum Bern, online at http://wsc.nmbe.ch, version 21.0, accessed on March 5, 2020.

Yaginuma, T. 1967. Revision and new addition to fauna of Japanese spiders, with descriptions of seven new species. Lit. Dep. Rev., Otemon Gakuin Univ., 1: 87-107.

Yaginuma, T. 1977. Spiders from limestone caves of Akiyoshi-dai Plateau, Yamaguchi Prefecture, Japan (II). Acta Arachnol., 27 special number: $1-21$.

Yaginuma, T. 1986. Spiders of Japan in colour -new eddition. Hoikusya, Osaka, 350pp. (In Japanese)

Zhang, X. \& Marusik, Y. M. 2016. A survey of Pireneitega from Tajikistan (Agelenidae, Coelotinae). Zookeys, 635: 89-107.

Zhang, X., Zhao, Z, Zheng, G. \& Li, S. 2016a. Nine new species of the genus Pireneitega Kishida, 1955 (Agelenidae, Coelotinae) from Xinjiang, China. Zookeys, 601: 49-74.

Zhang, X., Zhao, Z, Zheng, G. \& Li, S. 2016b. A further study of the spider genus Notiocoelotes (Araneae, Agelenidae) from Hainan Island, China. Zookeys, 601: 75-87.

Zhao, Z. \& Li, S. 2016. Papiliocoelotes gen. n., a new genus of Coelotinae (Araneae, Agelenidae) spiders from the Wuling Mountains, China. Zookeys, 585: 33-50.

Zhao, Z. \& Li, S. 2017. Extinction vs. rapid radiation: the juxtaposed evolutionary histories of coelotine spiders support the Eocene-Oligocene orogenesis of the Tibetan Plateau. Syst. Biol., 66: 988-1006.

Received March 23, 2020/ Accepted August 5, 2020 